\title{
Comparative Pollution Contribution of Three Point Sources of Pollution to Urban Drainage Stream Degradation, Uyo
}

\author{
Obot Ekpo Essien* \\ Department of Agricultural and Food Engineering University of Uyo, Uyo, Nigeria \\ *Corresponding author: obotessien@uniuyo.edu.ng, obotessien@ymail.com
}

Received November 30, 2013; Revised January 27, 2014; Accepted February 20, 2014

\begin{abstract}
Three point sources of pollution of urban drainage stream, Uyo, namely: Municipal Solid Water Leachate effluent (MSWL), Municipal Waste Water (MWW) and Abattoir Waste Water (AWW),were identified and characterized using standard water examination methods to determine their constituent quality.Variance homogeneity, correlations of paired PS were tested with ANOVA and covariance using SPSS version 17. Paired samples correlations showed very high correlations $(\mathrm{R}=92-99 \%)$. However, when properties were disaggregated into similar elemental constituents and tested, AWW and MSWL (in wet season) showed variance difference in solids and nutrients; all others showed variance homogeneity in heavy metals. Selective monitoring and control of common critical constituent pollutants is recommended.
\end{abstract}

Keywords: point source pollution, pollution strength assessment, urban drainage stream, surface water quality monitoring and control, selective critical constituents

Cite This Article: Obot Ekpo Essien, "Comparative Pollution Contribution of Three Point Sources of Pollution to Urban Drainage Stream Degradation, Uyo.” American Journal of Water Resources, vol. 2, no. 1 (2014): 10-17. doi: 10.12691/ajwr-2-1-2.

\section{Introduction}

Urban drainage water comes from many sources flowing into urban drainage channel or stream as the receiving stream. Sajaul [1] stated that surface water quality deterioration is the impact of anthropogenic activities at the area of the stream. Buzzle.com [1,2] gave many causes of anthropogenic water pollution as organic, inorganic, municipal, industrial and agricultural causes. In the case of Uyo urban drainage stream, causes of water pollution include influent flows of municipal waste water (MWW), leachate effluent from municipal solid waste dumpsite (MSWL), nonpoint source (NPS) storm runoff (NPS-RO) and abattoir waste water (AWW) [3]. However, the NPS-RO is very dispersed, intermittent and seasonal, occurring mainly following rain events, hence it is rainy season occurrence. Therefore, its measurement is not concentrated at a specific location but is spatially distributed over the entire slope length and catchment area for which the entire stream length drains. Therefore, it is not point source (PS). The other sources, on the other hand, are polluting water which have specific locations on the stream and occur permanently or continuously or at repetitive discrete time intervals (daily interval generally)and serve as direct point sources (PS) contributors to urban drainage water pollution by generating liquid pollution loads into the urban drainage stream (UDS) in all seasons or all year round.
This daily influx of pollution flows into UDS cause environmental quality degradation [3], hence the use of the stream water is adversely affected. The stream water is used for dry season irrigation of riparian farms and recreational sites (eco-tourism), for cattle drinking, laundry and car washing, and also for off-stream fish pond, on-stream fish ponds and actual fishing and river-side recreation centres [3]. The stream flow velocity reduces drastically in dry season [4], hence concentrated PS inflow, depending on temporal profile and intensity, results in general water quality and environmental degradation, showing such effects as eutrophication and malodorous air pollution and increasing water anaerobicity (low DO), which condition is known to affect adversely other downstream users of the lotic stream water [5]. Thus, the pollution point sources may sustain quality degradation and economic deprivation of the safe use of the water source in a healthy environment apart from being the liquid waste receiving stream for the urban area.

Therefore knowing the comparative strength and temporal variation of the pollution point sources would identify their significant contributions to surface water degradation, and advance information for the planning and design of effective monitoring and TMDL control programme, as well as assist in selective or discriminatory remediation and similar technology selection for easy management of the quality control and pollution remediation facility on the water course or system (intechopen.com) [6,7]. 
Therefore the objectives of this research were: (1) to determine the seasonal pollution loads or constituents quality of PS pollution on the urban drainage stream,(2) to determine any significant variance homogeneity or otherwise in pollution strength between the identified point sources of water pollution, and (3) to recommend remedies.

\section{Material and Methods}

\subsection{Sampling Methods and Analysis}

Both the grab and composite samplingmethods [5] were used in collecting leachate and water samples. Locations of the point sources were established along the reach of the stream located in the ravine around the municipal waste dumpsite, Uyo (Figure 1). MSW leachate effluent arrived the drainage stream at the upstream just before the municipal waste water inlet while the abattoir waste water entered the stream at the middle section.Samples of MSW leachate and stream water were collected in triplicates from the stations at the same time, in the months of March, September, October and November 2010.

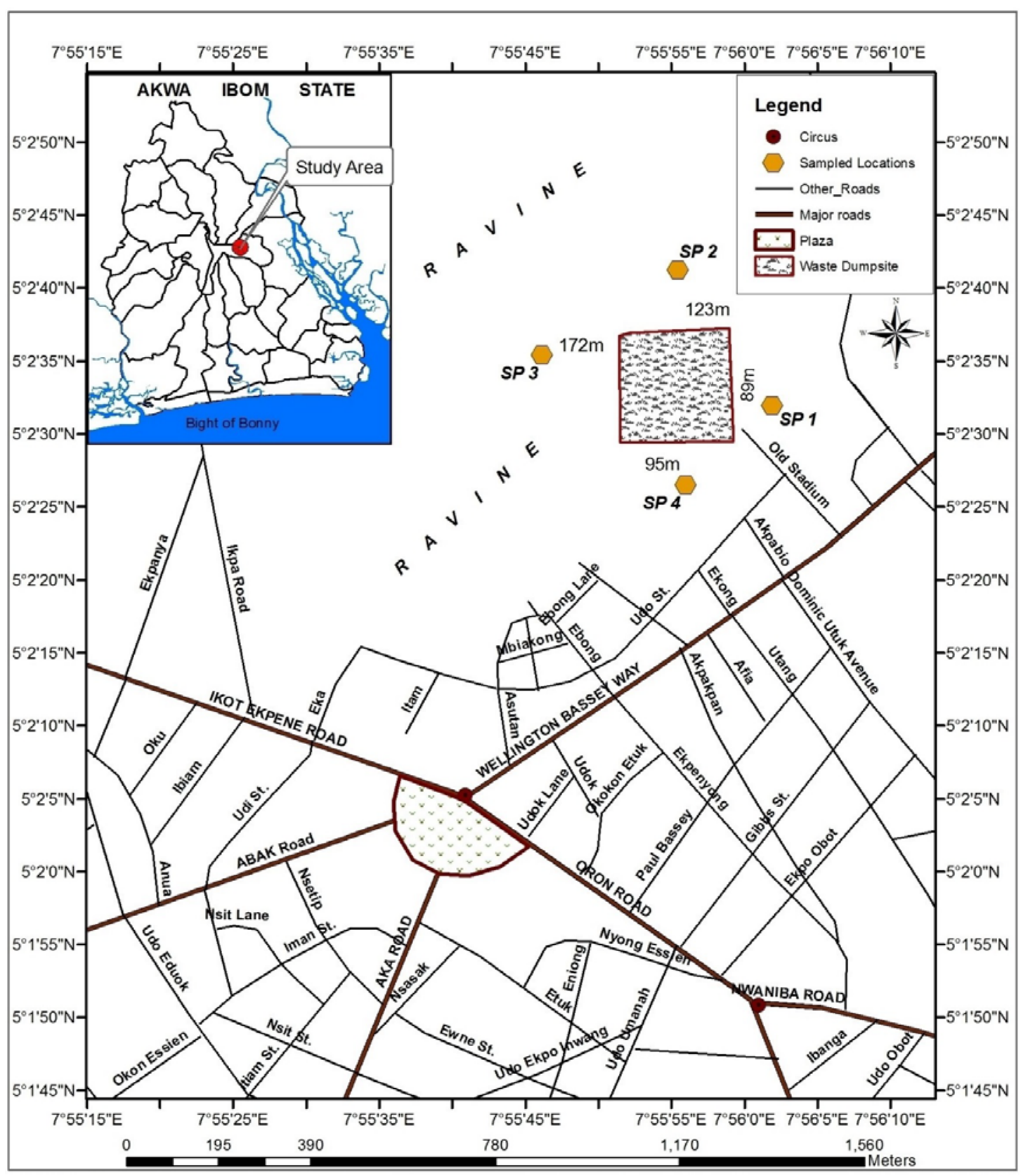

Figure 1. A cross section of Urban showing waste dumpsite and sampled locations

Since daily leachate production from MSW fluctuated during daily disposal, compaction and spread periods, [8]; the collection of its effluent sample was taken at three time intervals between 08.00 and 14.00hrs GMT on sampling days. Fresh leachate sample drained from the disposed heaps at dumpsite through chutes spillway into drain tank at the ravine base and was collected midway before dropping into the drain. The river samples were collected in all seasons at $300 \mathrm{~mm}$ below the water surface at the middle section. Properly labelled 1-litre transparent plastic bottles were used in collecting samples at site and properly corked to prevent spillage before being taken to the laboratory for some physical and chemical analyses. The $\mathrm{pH}$, temperature and electrical conductivity were measured on site. The samples were transferred in storage boxes to the laboratories of the University of Uyo and the Akwa Ibom Water Company (for chemical analysis) and the Aluminium Smelter Company of Nigeria (RUSAL- 
ALSCON) at Ikot Abasi, for heavy metals analysis. Sample bottles were thoroughly washed and rinsed with either leachate or stream water before respective uses. Sample bottles for waste water were placed horizontally facing the direction of flow to collect the water samples. Minimal air space was left in all bottles to accommodate any expansion of water in transit except those for BOD and DO tests.

\subsection{Analysis}

The on-site and laboratories test were carried out in accordance with American Public Health Association [9] and Federal Environmental Protection Agency of Nigeria [10] standards. The insitu measurements were carried out using Portable digital meter, EXECH PH-100 for $\mathrm{pH}$, digital EC/TDS/Temperature COM-100 for electrical conductivity (EC) and temperature; and Turbidimeter for Turbidity. The chemical analysis of total alkalinity (TA), total hardness (TH), Acidity and Chloride concentration were determined using titrimetrical techniques. The concentration of metals (Iron, Lead, and Calcium) were determined using $\mathrm{HACH}$ DR/2000direct reading spectrophotometer.

Determination of $\mathrm{Cu}, \mathrm{Zn}, \mathrm{Pb}$ was carried out by direct aspiration of the water samples into an air acetylene flame. Before determining any metal in the sample, a calibration curve of the metal was prepared using aliquots from standard stock solutions of the metal or salt of the metal in preparing the working standards. From the calibration curves, the concentration of the metals in the samples was determined. In addition, the concentrations of the metals in the samples were directly related to the concentration of the calibration curve as:

Adsorption concentration of metal $=($ Cc x As $) /$ Ac

where $\mathrm{Cc}=$ concentration of metal in calibration curve As = absorbance of sample

Ac $=$ absorbance in calibration curve.

Where dilution of the sample was carried out, the concentration of the metal was multiplied by the dilution factor. The stock solutions were usually of $1000 \mathrm{mg} / \mathrm{l}$. working standards were stored in plastic bottles instead of glass wares to prevent contamination.

For the determination of Iron, 10, 20, 30, 40 and $50 \mathrm{ml}$ standard Fe (11) solution respectively were pipetted accurately into five clean $100 \mathrm{ml}$ volumetric flasks, and 1 $\mathrm{ml} \mathrm{NH} 2 \mathrm{OH}, \mathrm{HCl}$ solution $1 \mathrm{ml}$ sodium was added to each flask. Each solution was diluted about $75 \mathrm{ml}$ with distilled water, and $10 \mathrm{ml}$ phenonthroline solution added to make up to $100 \mathrm{ml}$ mark with distilled water. It was shaken to mix thoroughly and allowed to stand for 10 minutes for complete colour formation. The absorbances on spectrophotometer was measured at $510 \mathrm{~nm}$. The readings were used to construct a calibration curve, and then measure the absorbance of iron in the sample.

Other water quality characteristics were evaluated using methods in $[9,10]$.

\subsection{Statistical Analysis}

The results of the sample analysis were subjected to statistical analysis (ANOVA, t-statistics and proportions) using SPSS version 17. Mean values of concentration of the parameters were computed and compared with each other and with standard values of $[11,12]$.

\section{Results and Discussion}

The mean concentrations of properties of the three PS pollution of Uyo urban drainage stream are given in Table 1 on selected relevant properties. The variables are AWW for Abattoir waste water, MWW for municipal waste water and MSWL, leachate for MSW leachate in dry season (and MSWLW leachate wet for municipal solid waste leachate in rainy season).

Table 1. Comparative result of water analysis from three PS on the Uyo drainage stream

\begin{tabular}{|l|c|c|c|c|}
\hline Description & \multicolumn{5}{|c|}{ Concentrations } \\
\hline Parameters & MSWL & MWW & AWW & NSDWQ \\
\hline \multicolumn{1}{|c|}{ Physical/organoleptic Properties } \\
\hline Colour & 15 & 30 & 30 & 15 \\
\hline Odour & Offensive & Offensive & Offensive & Unobjectionable \\
\hline Appearance & Brownish & Brownish & Cloudy & Clear \\
\hline $\begin{array}{l}\text { Temperature } \\
{ }^{\circ} \mathrm{C}\end{array}$ & 31 & 31 & 28 & Ambient \\
\hline $\mathrm{P}^{\mathrm{H}}$ & 9.30 & 9.38 & 7.30 & $6.5-8.5$ \\
\hline
\end{tabular}

\begin{tabular}{|c|c|c|c|c|}
\hline $\mathrm{P}^{\mathrm{H}}$ & 9.30 & 9.38 & 7.30 & $6.5-8.5$ \\
\hline \multicolumn{5}{|l|}{ Heavy Metal } \\
\hline Iron, Fe mg/l & 14.3 & 15.5 & 6 & 0.3 \\
\hline $\begin{array}{l}\text { Copper, } \mathrm{Cu} \\
\mathrm{mg} / \mathrm{l}\end{array}$ & 9.6 & 8 & 3 & 1.0 \\
\hline $\begin{array}{l}\text { Chromium, } \\
\text { Cr mg/l }\end{array}$ & 7.4 & 6.3 & $\begin{array}{l}\text { ND } \\
(\sim 0.5)\end{array}$ & 0.05 \\
\hline $\begin{array}{l}\text { Cadmium, } \\
\text { Cd mg/l }\end{array}$ & 1.1 & 0.8 & $\begin{array}{l}\text { ND } \\
(\sim 0.5)\end{array}$ & 0.003 \\
\hline $\begin{array}{ll}\text { Lead, } & \mathrm{Pb} \\
\mathrm{mg} / \mathrm{l} & \end{array}$ & 1.8 & 4.2 & $\begin{array}{l}\text { ND } \\
(\sim 0.5)\end{array}$ & 0.01 \\
\hline \multicolumn{5}{|l|}{ Nutrients } \\
\hline $\mathrm{PO} 4^{3} \mathrm{mg} / \mathrm{l}$ & 170 & 143.5 & 98.2 & 3.50 \\
\hline So4 ${ }^{2-} \mathrm{mg} / \mathrm{l}$ & 141 & 140 & 114 & 100 \\
\hline $\mathrm{NO}^{3-} \mathrm{mg} / \mathrm{l}$ & 294 & 300 & 288.5 & 50 \\
\hline $\mathrm{F}^{-} \mathrm{mg} / \mathrm{l}$ & 2.20 & 1.05 & 0.63 & 1.5 \\
\hline $\mathrm{C} \mathrm{L}^{-} \mathrm{mg} / \mathrm{l}$ & 21 & 25 & 21.3 & 250 \\
\hline $\mathrm{Na}^{+} \mathrm{mg} / \mathrm{l}$ & 65 & 93 & 923 & 200 \\
\hline $\mathrm{K}^{+} \mathrm{mg} / \mathrm{l}$ & 102 & 90 & 80.5 & \\
\hline $\mathrm{Ca}^{2+} \mathrm{mg} / \mathrm{l}$ & 114 & 98.3 & 90 & 75 \\
\hline $\mathrm{Mg}^{2+} \mathrm{mg} / \mathrm{l}$ & 43 & 35 & 30 & 0.20 \\
\hline \multicolumn{5}{|c|}{ Chemical Parameters } \\
\hline Acidity & 70 & 68 & 80 & $4.5-8.2$ \\
\hline $\begin{array}{l}\text { Total } \\
\text { Alkalinity }\end{array}$ & 145 & 146 & 135 & $100-200$ \\
\hline $\begin{array}{l}\text { Total } \\
\text { Hardness }\end{array}$ & 157 & 133 & 120 & 500 \\
\hline Salinity \% & 60 & 40 & 40 & 0.5 \\
\hline \multicolumn{5}{|c|}{ Solid Properties } \\
\hline TDS & 986 & 1235 & 824 & 500 \\
\hline TSS mg/l & 300 & 2,4 & 66 & 10 \\
\hline $\mathrm{TS} \mathrm{mg} / \mathrm{l}$ & $(1286)$ & $(15.04)$ & 880 & \\
\hline \multicolumn{5}{|l|}{ Oxides } \\
\hline $\begin{array}{ll}\mathrm{DO} & \left(\mathrm{O}_{2}\right) \\
\mathrm{mg} / \mathrm{l} & \\
\end{array}$ & 6.0 & 6.25 & 5.2 & $1.0-5.0$ \\
\hline COD & 10.18 & 1320 & 2450 & \\
\hline \multicolumn{5}{|l|}{ Biological } \\
\hline $\begin{array}{l}\text { Coliform, } \\
\text { counts } / 100 \mathrm{ml}\end{array}$ & 890 & 560 & 1630 & 10 \\
\hline $\begin{array}{l}\text { E-Coli, } \\
\text { counts/100ml }\end{array}$ & 890 & 560 & 350 & 0 \\
\hline $\begin{array}{l}\text { Number } \\
\text { (those with } \\
\text { mg/l Unit) }\end{array}$ & 28 & 29 & 30 & \\
\hline Mean & 237.42 & 271.25 & 223.81 & \\
\hline SD mg/l & 448.13 & 488.82 & 440.39 & \\
\hline $\mathrm{SE} \mathrm{mg} / \mathrm{l}$ & 84.69 & 90.77 & 80.40 & \\
\hline $\mathrm{CV} \%$ & 188.7 & 180.2 & 196.77 & \\
\hline
\end{tabular}

N/B: MSWL = Municipal Solid Waste leachate, MWW = Municipal waste water, $\mathrm{AWW}=$ abattoir waste water 
The disaggregation of measured properties into common subgroups with same units $(\mathrm{mg} / \mathrm{l})$ was made for easy comparison. Hence, MSWL(dry season) had 28 items, MWW had 29 and AWW variables contained 30 items.

The range of dispersion from mean was very wide in all variables (Table 1) as observed from the closeness of their $\mathrm{SD}$ values, although the SE values werenearly the same, showing that their values were almost within the same degree of pollution concentration. The high CVs, although of the same level in values (Table 1), indicated that very high variability, however, existed in their water pollution characteristics as point sources. This is realistic as the different parameters in Table 1 do not have the same maximum concentration in any medium in nature.
A test of variance (ANOVA) gave $F$ calculated as 0.921and less than the F, indicating that homogeneity of their variance should be accepted as null hypothesis. As such, there is no significant difference between the pollution degrees of the three point sources although the concentrations of their constituents vary. However, the degree of their variation or how their concentrations per PS varied would be qualified by paired samples test.

\subsection{Paired Sample Test of Total PS Quality}

Table 2 shows the combined paired sample statistics and correlation test results of the three PS.

Table 2. Paired sample statistics and correlations of three PS pollution on urban drainage stream

\begin{tabular}{|c|c|c|c|c|c|c|c|}
\hline Paired set & Mean mg/L & $\mathrm{N}$ & $\mathrm{SD}$ mg/L & $\mathrm{CV} \%$ & $\mathrm{SE} \mathrm{mg} / \mathrm{L}$ & $\mathrm{R}$ & SIG \\
\hline $\begin{array}{l}\text { Abattoir } \\
\& \\
\text { MWW }\end{array}$ & $\begin{array}{l}219.46 \\
271.25\end{array}$ & 29 & $\begin{array}{l}447.53 \\
488.82\end{array}$ & $\begin{array}{l}18.6 \\
18.6 \\
\end{array}$ & $\begin{array}{l}83.104 \\
90.772\end{array}$ & 0.1757 & .000 \\
\hline $\begin{array}{c}\text { Abattoir } \\
\& \\
\text { Leachcate Dry }\end{array}$ & $\begin{array}{l}206.59 \\
237.42\end{array}$ & 28 & 436.96 & $\begin{array}{l}18.9 \\
18.9\end{array}$ & $\begin{array}{l}82.577 \\
84.688\end{array}$ & 0.0921 & .000 \\
\hline $\begin{array}{l}\text { Leachcate Dry } \\
\qquad \& \\
\text { Leachcate wet }\end{array}$ & $\begin{array}{l}234.42 \\
216.28\end{array}$ & $\begin{array}{l}28 \\
28\end{array}$ & $\begin{array}{l}448.13 \\
434.56 \\
\end{array}$ & $\begin{array}{l}18.9 \\
18.9\end{array}$ & $\begin{array}{l}84.688 \\
82.125 \\
\end{array}$ & 0.957 & .000 \\
\hline $\begin{array}{c}\text { MWW } \\
\& \\
\text { Leachcate Dry }\end{array}$ & $\begin{array}{l}196.71 \\
213.25\end{array}$ & $\begin{array}{l}27 \\
27\end{array}$ & $\begin{array}{l}416.57 \\
437.67\end{array}$ & $\begin{array}{r}18.9 \\
19.25\end{array}$ & $\begin{array}{l}80.109 \\
84.230\end{array}$ & 0.977 & .000 \\
\hline $\begin{array}{c}\text { Abattoir } \\
\& \\
\text { Leachcatewet }\end{array}$ & $\begin{array}{l}201.19 \\
140.54\end{array}$ & 29 & $\begin{array}{r}430.07 \\
446.29\end{array}$ & $\begin{array}{l}18.6 \\
18.6\end{array}$ & $\begin{array}{r}79.862 \\
82.874 \\
\end{array}$ & 0.737 & .000 \\
\hline
\end{tabular}

N/B: N= number of properties; SD =standard deviation, SE = standard error, R =correlation coefficients, SIG= significant level.

\subsection{Comparison of Total Quality of PS Pollution}

The total chemical composition of the three pollution PS of similar properties in Table 1 were compared by paired sample statistics and paired samples correlations. The array of selected paired statistics, correlations and significance are shown in Table 2. Each pair of PS exhibited marked standard deviation but their standard errors were clearly within the same range of concentration level of 80-91 mg/l, with a covariance of only $19 \%$ for the pool of PS pairs which indicated that each pair, varied in the same degree at equidistant values or at equal interval from their means, which varied only slightly between 196.71 and 271.25 $\mathrm{mg} / \mathrm{l}$. This means that pollution point sources were nearly similar in the concentrations of their pollutants composition.

The paired samples correlation coefficients for each pair of PS were all very strong and significant $(\mathrm{P}<0.010)$ (Table 2). That means the pollution degree in each point source was similar (with $\mathrm{R}=92.1 \%$ to $\mathrm{R}=97.7 \%$ or mean $\mathrm{R}=95 \%$ ). The high correlations were as follows: Abattoir \& leachate Dry $(\mathrm{R}=92.15 \%)$ leachate Dry\& leachate wet (95.7\%), leachate Dry \& MSS (R=97.7\%). For Abattoir \& MSS and Abattoir \& leachate wet, the strength of the polluting relationship was just strong. Thus, each PS has similar regressive effect on the receiving water; hence the receiving water has a multiple regression relations with the independent variables (the PS constituents' concentrations). The constituents of the PS solution constituted independent variables that significantly affected the receiving water. The three PS effect on receiving water constituted three regressions of PS pollution quality on receiving water quality.
In multiple regression, the effects of the independent variables are additive. Thus the three PS constituted combined or additive effect on the pollution loading of the receiving water. They added to each other's effect and produced synergy effect on the urban drainage stream. Thus, if the pollution components in receiving water is of $\mathrm{q}$, then the additive sum of pollution effects from the three PS constituents can give a multiple regression function as:

$$
\mathrm{q}=\mathrm{a}+\mathrm{b}_{1} \mathrm{PS}_{1}+\mathrm{b}_{2} \mathrm{PS}_{2}+\mathrm{b}_{3} \mathrm{PS}_{3}
$$

where $\mathrm{q}$ is dependent quality on the combined PS quality in receiving water, PS properties are predictors and a, b are coefficients.

For instance, for chemical copper cation, $\mathrm{Cu}$,

$$
\mathrm{Cu}_{1}=\mathrm{a}+19.6 \mathrm{~b}+\mathrm{b} 28+\mathrm{b}_{3}+\text { interactive terms }
$$

Or,

$$
\mathrm{Cu}_{1}=\mathrm{a}+96 \mathrm{~b}+8 \mathrm{~b}^{2}+3 \mathrm{~b}^{3}
$$

where $\mathrm{Cu}_{1}$ is predictor constituent group.

Using other temporal data, a whole set of determinants in PS coefficients can be arranged to solve for the unknown interactive coefficients.

Table 2 shows the ANOVA for the three PS pollution on urban drainage stream. The ANOVA indicated no significant difference between the qualities of pollution point sources. This confirmed the very strong significant correlation and the homogenous variations of PS properties from their means.

Comparison of groups of similar element in the PS: Chemical components of the pollution PS were also analyzed in disaggregated groups of similar elements such as heavy metals, nutrients, solids and physical properties. 


\subsection{Heavy Metals (HM) in PS}

Paired sample t-tests of heavy metals in PS, their correlation and significance are shown in Table 3.

The mean values of $\mathrm{HM}$ in the point sources of pollution were low. The five HM in each PS varied widely (CV> 78 -115.9\%) for Abattoir, MWW, Leachate Dry and Leachate Wet. Their PS pairs (Table 4) exhibited very strong positive correlations $(\mathrm{R}=0.892-0.995)$. The least correlations coefficient, $(\mathrm{R}=0.892$ was for the pair Abattoir -vs- MWS leachate, while the strongest correlation of $\mathrm{R}=0.995$ was for the paired PS: Leachate Wet\& Leachate Dry. The high positive correlation in all paired PS shows that HM value in all the pollution PS were similar to each other in pollution strength (Table 4).

Table 3. HM statistics in paired PS pollution of urban drainage stream

\begin{tabular}{|c|c|c|c|c|c|c|}
\hline \multirow{2}{*}{ Statistics } & \multicolumn{6}{|c|}{ Statistical Values } \\
\hline & Pair 1 & Pair 2 & Pair 3 & Pair 4 & Pair 5 & Pair 6 \\
\hline \multicolumn{7}{|l|}{ HM Correlations } \\
\hline $\mathrm{N}$ & 5 & 5 & 5 & 5 & 5 & 5 \\
\hline $\mathrm{R}$ & 0.929 & 0.892 & 0.913 & 0.955 & 0.945 & 0.995 \\
\hline Sig & 0.22 & 0.042 & 0.030 & 0.012 & 0.015 & 0.000 \\
\hline $\mathrm{P}$ & $\mathrm{P}<0.05$ & $\mathrm{P}=0.05$ & $\mathrm{P}=0.05$ & $\mathrm{P}=0.05$ & $\mathrm{P}=0.05$ & $\mathrm{P}>0.01$ \\
\hline SD & 3.338 & 3.527 & 7.344 & 1.657 & 4.678 & 4.049 \\
\hline SE & 1.493 & 1.577 & 3.284 & 0.741 & 2.092 & 1.811 \\
\hline $\mathrm{t}$ & -3.256 & -3.005 & -2.704 & 0.1624 & 1.921 & -2.286 \\
\hline $\mathrm{df}$ & 4 & 4 & 4 & 4 & 4 & 4 \\
\hline Sig (2-tailed) & 031 & 040 & .021 & .879 & 127 & .084 \\
\hline
\end{tabular}

N/B: Pair 1= Abattoir/MWW; pair 2= Abattoir / Leachate Dry; Pair 3 = Abattoir/ Leachate wet; Pair 4 = MWW/Leachate Dry; pair 5 = Surface/leachate wet; pair 6 = leachate dry/ leachate wet

The paired PS samples showed significant differences at $5 \%$ only in pairs 1,2 and 3 , while pair 6 showed significance at $10 \%$ only. That also indicated differences in HM content when paired PS are rotated. The significant difference occurred in PS pairs 1, 2and3, but for pairs 4 and 5, high HM values were comparable in both sources (variables). Heavy metals (HM) in Abattoir showed significant difference at $5 \%$ from HM in Leachate Dry in dry season. Also, HM in dry season was significantly

different from HM in wet season leachate (MSWLW) at $8 \%$. This was in line with earlier observation of high HM [14].

\subsection{Nutrient Contents in PS Compared}

Nutrient concentrations in PS pollution were also blogged for comparison. Table 4 indicates the results for nutrients properties.

Table 4. Nutrient properties of three PS compared

\begin{tabular}{|c|c|c|c|c|c|c|}
\hline \multirow{2}{*}{$\begin{array}{c}\text { Statistic } \\
\text { Description }\end{array}$} & \multicolumn{6}{|c|}{ Statistical values of in PS pair } \\
\hline & Pair 1 & Pair 2 & Pair 3 & Pair 4 & Pair 5 & Pair 6 \\
\hline $\mathrm{N}$ & 9 & 9 & 9 & 9 & 9 & 9 \\
\hline $\mathrm{R}$ & .987 & .954 & .981 & .985 & .999 & .988 \\
\hline Sig & .000 & .000 & .000 & .000 & .000 & .000 \\
\hline $\mathrm{P}$ & $\mathrm{P}<0.01$ & $\mathrm{P}<0.01$ & $\mathrm{P}<0.01$ & $\mathrm{P}<0.01$ & $\mathrm{P}<0.01$ & $\mathrm{P}<0.01$ \\
\hline
\end{tabular}

Paired Sample Test

\begin{tabular}{|c|c|c|c|c|c|}
\hline M & & & & & \\
\hline SD & 14.594 & 26.905 & 21.156 & 15.484 & 8.380 \\
\hline SE & 4.865 & 8.968 & 7.052 & 5.161 & 2.793 \\
\hline T & -2.522 & 5.484 & -1.868 & 8.974 & 0.594 \\
\hline Df & 8 & 8 & 8 & 8.165 & 8 \\
\hline Sign. (2 tailed) & .036 & .129 & .033 & .586 & .069 \\
\hline P & $\mathrm{P}=.05$ & Ns & $\mathrm{P}<0.05$ & $\mathrm{n}$ & .586 \\
\hline
\end{tabular}

All the nutrient pairs correlated very strongly $(\mathrm{R}=98.1$ $-98.8 \%$ and $99.9 \%$ ), and very significant $(\mathrm{P}<0.01$ ) (Table 4). That means the level of nutrients in PS was generally very high [13]. However, the significant difference between the paired PS components, stood out pairs 1, 3 and 5 (Table 4) only as being significantly different from nutrients in conjugate PS. From Table 4, Abattoir/MWW, Abattoir/Leachate wet, and MWW/Leachate wet had significant differences $(\mathrm{P}<0.05)$ between their properties while Abattoir/Leachate Dry and MWW/Leachate Dry and Leachate Wet/Leachate Dry did not show explicit difference. Hence, PS concentrations in all seasons were comparable. Nutrients in paired PS show that nutrients in Abattoir were not comparable with components in
Leachate Wet and municipal waste water. They had inconsistent nutrient pollution levels in the three PS whereas in the dry season the nutrients components pollution were comparable in Leachate Dry \&Abattoir.

\subsection{Solids Component in Three PS Compared}

Paired t-test for solid contents in the three PS showed very significant and high correlations between their pairs ( $\mathrm{P}<0.01, \mathrm{R}=1.0$ ), except with Abattoir/ MWW where $\mathrm{R}=0.999$ at $\mathrm{P}=0.27$ (i.e. less than $5 \%$.). The dispersion in solids in each PS was very wide, giving a large SE and large variability for the mean $(\mathrm{CV}=60.0-123.2 \%)$. The variability of solids in the pairs of Abattoir \& leachate Dry 
and Abattoir \& Leachate wet were the highest (123.2\%), suggesting serious anthropogenic pollution.

The significant difference between members of each pairs varied differently. Only Abattoir \& MWW and Abattoir \& Leachate wet had significant difference at 5\% while the other four pairs had no significant relationship. They justified the hypothesis of variance homogeneity in strength of solid pollution of urban drainage stream.

Urbanization in the expanding urban create poor sanitary condition leading to increased waste generation littered at corners. Rainfall runoff in this heavy rainfall region washed them into the poorly distributed drainage system and then into the urban drainage stream [7].

The high solids content in MWW follows the construction debris, traffic dust etc. Urban runoff carries all sorts of pollutants for waste generation sites - homes, roads, industries, riparian farms, construction sites with laterite dust, MSW dumpsite.

\subsection{Graphical Comparison}

Comparison of chemical constituents in the three PS is further shown by graphical representations in Figure 2, Figure 3 and Figure 4 showing differences in the constituent elements between the three PS pollution. The combined three PS pollution (blue colour in Figure 1, Figure 2, Figure 3 and Figure 4) gave higher mean values of pollution properties than the unpolluted stream (pink colour); and both showed lower pollution concentration than MSW leachate (grey colour in Figure 1).

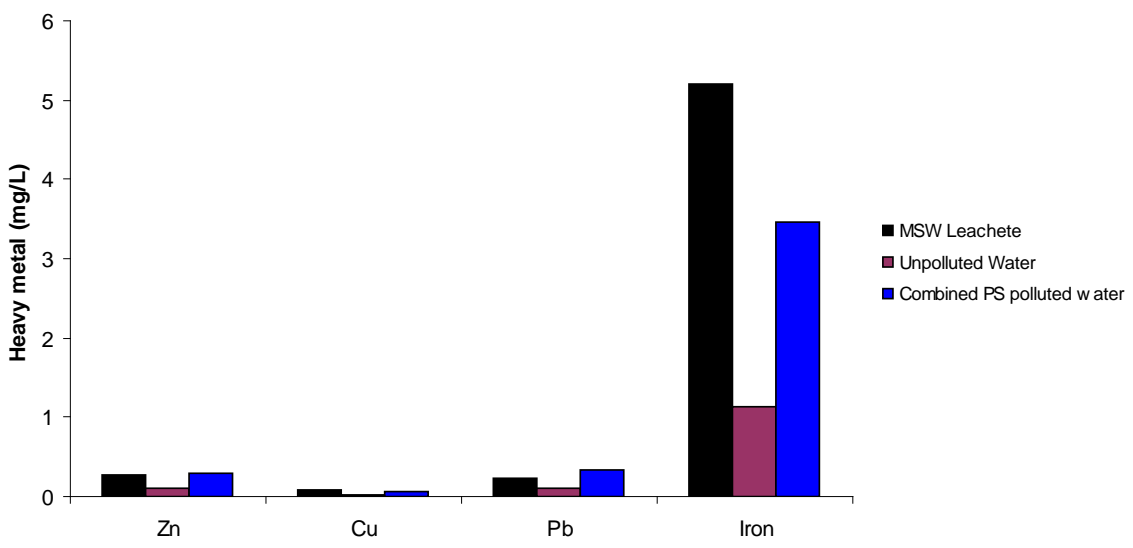

Figure 2. Comparison of Heavy metals inthe combined three PS, clear stream water and the Leachate. PS of pollution on urban drainage stream

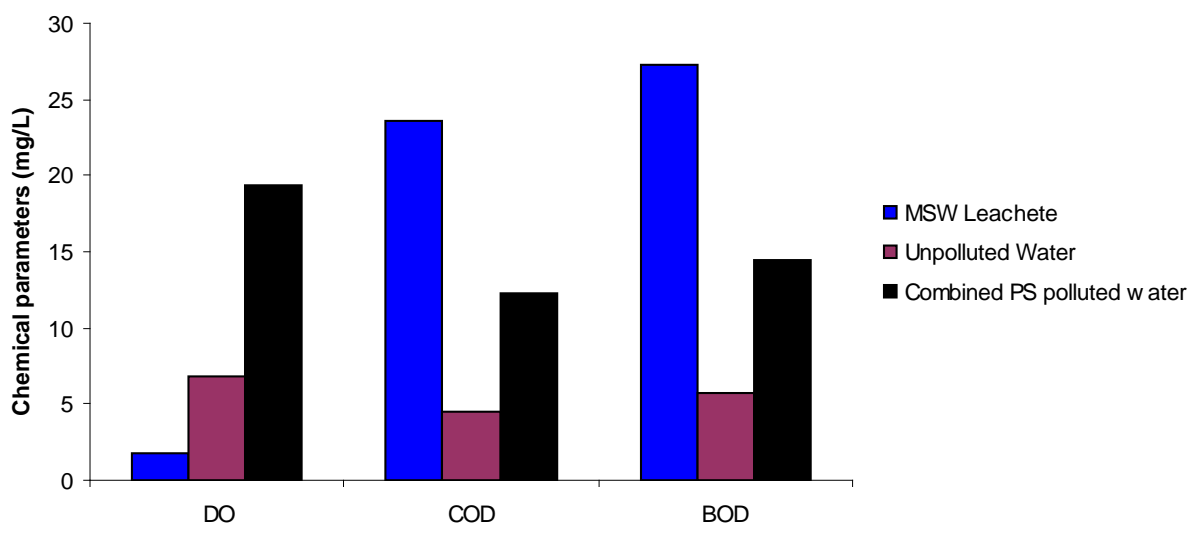

Figure 3. Chemical parameters (DO, COD and BOD) compared in the combined three. PS, clear stream water and the Leachate PS on urban drainage stream

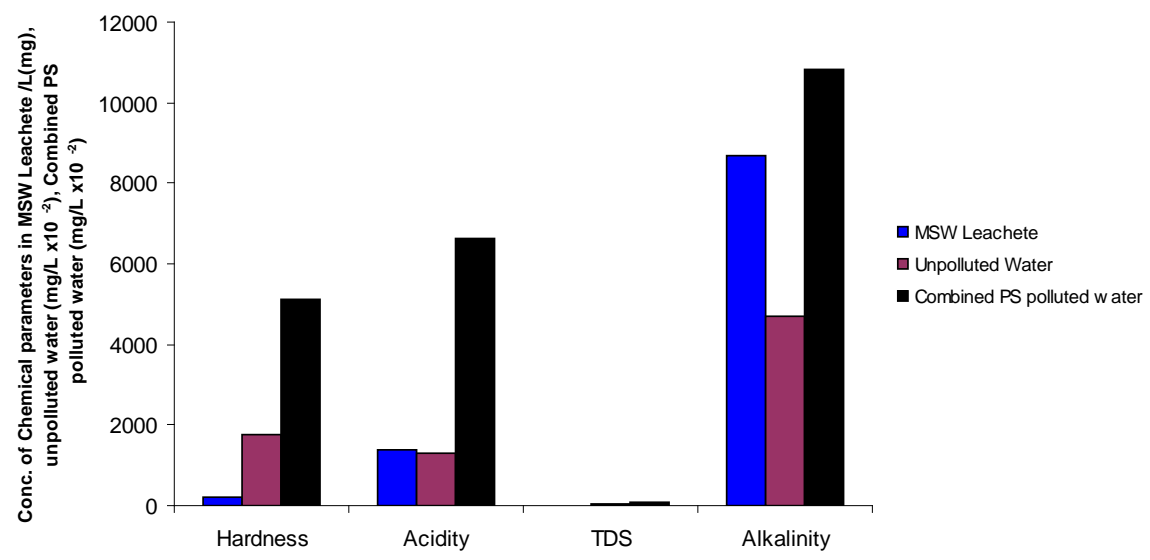

Figure 4. Hardness, Acidity, TDS and Alkalinity compared in three combined. PS, clear stream water and the Leachate PS on urban drainage stream 


\subsection{Physical Properties in the Three PS}

The correlation of physical properties in the pairs of PS varied differently. Only physical properties in Abattoir \& MWW and Abattoir \& Leachate wet were not correlated ( $\mathrm{R}=0.167-0.227$ ), but the other four pairs correlated very strongly at $\mathrm{R}=0.816-0.933$. The correlations were significant as follows: Abattoir \& Leachate dry $(\mathrm{R}=.810$, $\mathrm{P}=.05)$; MWW \& leachate Dry $(\mathrm{R}=.981, \mathrm{P}<0.01)$ and MWW \& leachate wet $(\mathrm{R}=.845, \mathrm{P}<0.05)$.

The physical properties however had no basic significant differences between their levels of pollution in the three point sources.

\subsection{Hypotheses Result}

From the foregoing, the following theses were obtained:

Variance homogeneity existed between the three pollution point sources, nominally putting them at the same degree of pollution by the level of their constituents' concentrations in the drainage stream pollution $(\mathrm{P}<0.01)$.

Disaggregated groups showed variance PS. Thus, variance homogeneity were in selective subgroups of the three PS. Hence, selective control of common critical elemental pollution in PS components would form the bases of pollution monitoring and control program on urban drainage stream. Components such as solids were higher in Abattoir and Leachate Dry than the degree of pollution of the HM varied on constituent elemental basis between the PS but high positive correlation shows that control treatment could be of the same for the three point sources of pollution.

Abattoir waste water (AWW), municipal waste water (MWW) and municipal solid waste leachate (wet season) (MSWLW) were not compatible in nutrient composition monitoring and TMDL should note critical constituent levels but remediation should be a studied programme.

\subsection{Variability and Synergy of Point Sources Pollution}

Table 5 shows the properties of the clear water stream (CWS) which is the normal stream water quality without the PS pollution (except perhaps the nonpoint source runoff). Also shown are properties of the combined PS polluted drainage stream (CPDS). It can be observed that all the PS properties are different from the CWS properties, showing that, apart from NPS-RO which is a common factor, the PS pollution are grossly degraded and cannot safeguard the stream quality. On the other hand, the CPDS is grossly denatured by the combined effect (additive effect) of the PS pollution.

The significant difference between each of the CWS and CPDS shows in the geometric means of their properties. The geometric mean of the nominal properties where in increasing order.

$$
2.02(\text { CWS })<4.91 \text { (CPDS) < } 19.46(\text { MSWL) }
$$

The geometric means of the heavy metal in the CWS, CPDS and MSWL (dry) were in the order:

$$
0.18 \text { (CWS) }<0.32 \text { (CPDS) }<0.4 \text { (MSWL) }
$$

In all cases, the mean of CWS was the least indicating it is unpolluted.

\subsection{Solution to urban stream pollution problems}

The critical physico-chemical properties(like HM) which are at the same order of pollution in the 3 PS and the ones that are identified with some pairs of PS can be used for selective index of monitoring of urban drainage water pollution. This aligns with the objective of [16] in assessment of Oyun reservoir in the Kwara state of Nigeria.

Therefore, this study advances solution for pollution of urban drainage streams for Uyo municipality as in [6]. Urgent monitoring as well as enforcement emission standards are needed to mitigate the growing pollution of urban drainage stream in Uyo metropolis from assorted causes especially the point source pollution.

Table 5. Chemical parameters of combined PS polluted drainage

\begin{tabular}{|c|c|c|}
\hline Parameters & $\begin{array}{c}\text { Unpolluted Clean } \\
\text { Stream }\end{array}$ & $\begin{array}{c}\text { Combined PS } \\
\text { Polluted down stream }\end{array}$ \\
\hline Zine mgl- $^{1}$ & $\begin{array}{c}0.096 .099 \\
0.097 \pm 0.002\end{array}$ & $\begin{array}{c}0.290-.300 \\
0.294 \pm 0.006\end{array}$ \\
\hline Copper mgl ${ }^{-1}$ & $\begin{array}{c}0.01-0.025 \\
0.0910 \pm .006\end{array}$ & $\begin{array}{l}0.046-0.068 \\
0.056 \pm 0.011\end{array}$ \\
\hline Lead $\mathrm{mgl}^{-1}$ & $\begin{array}{c}0.091-0.104 \\
0.097 \pm 0.007\end{array}$ & $\begin{array}{c}0.323-0.347 \\
0.334 \pm 0.012\end{array}$ \\
\hline Sodium $\mathrm{mgl}^{-1}$ & $\begin{array}{c}5.650-7.340 \\
6.577 \pm 0.857 \\
\end{array}$ & $\begin{array}{l}17.226-23.840 \\
20.789 \pm 3.337 \\
\end{array}$ \\
\hline Siliiea $\mathrm{mgl}^{-1}$ & $\begin{array}{c}0.006-0.012 \\
0.009 \pm 0.003 \\
\end{array}$ & $\begin{array}{c}0.024-0.044 \\
0.033 \pm 0.010 \\
\end{array}$ \\
\hline $\mathrm{DO} \mathrm{mgl}^{-1}$ & $\begin{array}{c}5.675-7.320 \\
6.592 \pm 0.839 \\
\end{array}$ & $\begin{array}{l}16.324-21.300 \\
18.985 \pm 2.506 \\
\end{array}$ \\
\hline $\mathrm{COD} \mathrm{mgl}^{-1}$ & $\begin{array}{c}3.700-5.870 \\
4.680 \pm 1.100 \\
\end{array}$ & $\begin{array}{c}10.240-14.00 \\
12.193 \pm 1.884 \\
\end{array}$ \\
\hline $\mathrm{BOD}_{3} \mathrm{mgl}^{-1}$ & $\begin{array}{c}4.580-6.330 \\
5.543 \pm 0.888 \\
\end{array}$ & $\begin{array}{l}11.428-16.400 \\
14.089 \pm 2.504 \\
\end{array}$ \\
\hline Temperature C & $\begin{array}{c}26.100-26.700 \\
26.33 \pm 0.321 \\
\end{array}$ & $\begin{array}{l}26.400-26.600 \\
26.533 \pm 0.115 \\
\end{array}$ \\
\hline $\mathrm{PH}$ & $\begin{array}{l}6.700-8.300 \\
7.46 \pm 0.802 \\
\end{array}$ & $\begin{array}{c}8.400-13.600 \\
11.733 \pm 2.894 \\
\end{array}$ \\
\hline Hardness $\mathrm{mgl}^{-1}$ & $\begin{array}{l}15.500-19.600 \\
17.633 \pm 2.055 \\
\end{array}$ & $\begin{array}{l}44.000-56.600 \\
50.507 \pm 6.317 \\
\end{array}$ \\
\hline Acidity $\mathrm{mgl}^{-1}$ & $\begin{array}{l}11.050-16.500 \\
13.583 \pm 2.745 \\
\end{array}$ & $\begin{array}{l}60.000-74.500 \\
66.900 \pm 7.275\end{array}$ \\
\hline Conductivity us $\mathrm{cm}^{-1}$ & $\begin{array}{c}42.00-18.00 \\
45.333 \pm 3.055\end{array}$ & $\begin{array}{c}96.000-105.00 \\
101.00 \pm 4.583\end{array}$ \\
\hline Chloride $\mathrm{mgl}^{-1}$ & $\begin{array}{c}121.50-129.50 \\
125.8 \pm 4.034 \\
\end{array}$ & $\begin{array}{l}271.00-284.60 \\
275.79 \pm 7.636 \\
\end{array}$ \\
\hline $\mathrm{TDS}_{\mathrm{mgl}} \mathrm{l}^{-1}$ & $\begin{array}{c}0.10-0.600 \\
0.333 \pm 0.252\end{array}$ & $\begin{array}{c}0.330 .1 .320 \\
0.867 \pm 0.500\end{array}$ \\
\hline Alkalinity $\mathrm{mgl}^{-1}$ & $\begin{array}{l}43.100-51.300 \\
47.200 \pm 4.100\end{array}$ & $\begin{array}{c}93.33-118.90 \\
106.81 \pm 12.84\end{array}$ \\
\hline Iron $\mathrm{mgl}^{-1}$ & $\begin{array}{c}0.985-1.350 \\
1.157 \pm 0.183\end{array}$ & $\begin{array}{c}2.503-4.460 \\
3.471 \pm 0.979\end{array}$ \\
\hline Sulphate $\mathrm{mgl}^{-1}$ & $\begin{array}{c}0.120-1.700 \\
0.710 \pm 0.863\end{array}$ & $\begin{array}{c}0.440-4.750 \\
2.080 \pm 2.332 \\
\end{array}$ \\
\hline Nitrate $\mathrm{mgl}^{-1}$ & $\begin{array}{c}1.500-1.950 \\
1.717 \pm 0.225\end{array}$ & $\begin{array}{c}3.610-6.040 \\
4.800 \pm 1.216\end{array}$ \\
\hline Ammonium mgl ${ }^{-1}$ & $\begin{array}{l}0.144-0.412 \\
0.303 \pm 0.141 \\
\end{array}$ & $\begin{array}{c}1.035-1.397 \\
1.236 \pm 0.184 \\
\end{array}$ \\
\hline Calcium mgl ${ }^{-1}$ & $\begin{array}{l}21.600-28.300 \\
25.100 \pm 3.360\end{array}$ & $\begin{array}{c}52.104-63.10 \\
57.935 \pm 5.528\end{array}$ \\
\hline
\end{tabular}
stream compared to unpolluted clean stream

\section{Conclusion}

Three point sources (PS) of pollution on Uyo urban drain stream were identified and characterized and their 
pollution load contribution to receiving urban drainage river were assessed using SPSS version 17.0.

The three identified PS were Municipal Solid Waste Leachate (dry and wet season), Municipal Waste Water and Abattoir Waste Water and entered the urban drainage stream as concentrated flow at specific locations in the stream channel.

The three PS showed significant variance homogeneity nominally but when segregated into elemental components and tested by paired samples statistics, some showed no significant correlation, for instance, Abattoir Waste Water and Municipal Solid Waste Leachate in wet season had significant variance difference at $10 \%$ for solid and nutrients.

The three PS showed significant variance homogeneity in heavy metal component where they had common degree of pollution strength monitoring and control programme based on selective critical constituents is recommended.

\section{References}

[1] Sajaul I., Hossain, M. A., Nasly, M. A. and Sobahan, M. A.,"Effect of industrial pollution on the spatial variation of surface water quality”. American Journal of Environmental Sciences, 9 (2): 120-129, 2013.

[2] Buzzle.com Causes of water pollution. www.buzzle.com/--cles/causes-of-water-pollution.html.

[3] Etok U. E, Distribution of non-point source (NPS) pollutants on AkpatakEka and Obot Uyo streams, Uyo Local Government Area. BSc Project, Faculty of Engineering, University of Uyo, Uyo, 2008.
[4] Archibong, D. and Archibong E., Field investigation of soil and water characteristics at abandoned municipality dumpsite, Uyo. BSc Project report, Faculty of Engineering, University of Uyo, Uyo, 2011.

[5] Metcalf and Eddy, Engineering treatment disposal and re-use, $3^{\text {rd }}$ edition, McGraw-Hill, New York, 2003.

[6] Ekiye, Zejiao, "Surface water quality monitoring in Nigeria". African Journal of Environmental Science and Technology, Vol. 2, 2010. www.intechopen.com/download/pdf/35057.

[7] Taiwo, A. M., Olujimi, O. O., Bamgbose, O. and Arowolo, T. A., "Surface water quality monitoring in Nigeria: Situational analysis and future management strategy", Water Quality Monitoring and Assessment, DrVaudour's Ed, Intech, 2012.

[8] Ikpeh, I. J., Quality of leachate from waste dumpsite and effect on downstream river quality in Uyo, BSc project report, Faculty of Engineering, University of Uyo, Uyo, 2008.

[9] APHA, Standard methods for the examination of water and wastewater, 18th edition. American Public Health Association, Washington DC, 1992.

[10] FEPA, Guidelines and standard for environment pollution control in Nigeria. Federal Environmental Protection Agency, Abuja, 1991.

[11] WHO, Guidelines for drinking water quality, $4^{\text {th }}$ edition, World Health Organization, Geneva, 2011.

[12] SON, Nigerian standards for drinking water quality (NSDWQ), Industrial standards. SON, 554, 1-14, 2007.

[13] Brodie, $M$ and Mitchell, R., Nutrients in African tropical rivers changes with agricultural development and implication for receiving rivers. The Environmentalist, 23: 709-715.

[14] Essien, O. E., "Basin-scale temporal distribution of water resources and sensitivity of components contribution in Ikpa catchment of Nigeria, Global Journal of Engineering and Technology, 2 (2): 147-153, 2009.

[15] EPA, "Surface water quality monitoring \& Assessment Programmes”. www.epa-stae.il,ws/water/surface-water/index.html.

[16] Mustapha, M.K, “Assessment of the water quality of Oyun reservoir, Offa, Nigeria usingselected physico-chemical parameters". Turkish Journal of Fisheries and Aquatic Sciences, 8 (2): 309-319. 